\title{
HIGH AND LOW WATER PREDICTION AT LAGOS HARBOUR, NIGERIA
}

\author{
0. T. Badejo ${ }^{1, *}$ and S. 0. Akintoye ${ }^{2}$

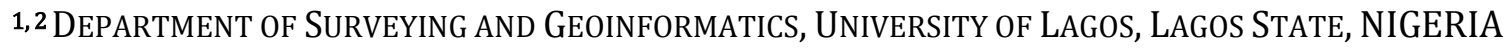 \\ E-mail addresses. ${ }^{1}$ shegunbadejo@yahoo.com, ${ }^{2}$ samolumide10@gmail.com
}

\begin{abstract}
In this work, 500 hourly water level tidal data were used to perform least squares tidal harmonic analysis. Eleven tidal constituents were used for the harmonic analysis. Astronomical arguments $(v+u)$ and the nodal factor $(f)$ were computed for each tidal constituent and at each observational period with a programme written in Matlab environment. The harmonic constants determined from the least squares tidal harmonic analysis were substituted into a tidal prediction model to predict hourly tidal data and tidal predictions at 5 minutes' intervals. Series of high and low water heights from the tidal predictions made at 5 minutes' intervals were determined and matched with their corresponding times. Autocorrelation at lags 1 to 30 for the residuals of the observed and predicted tidal data shows that there is no significant correlation in the range of the 30 lags. The series of residuals of the observed and predicted tidal data is therefore white noise.
\end{abstract}

Keywords: harbor, tidal harmonic analysis, tidal prediction model, water level.

\section{INTRODUCTION}

Tides are periodic rises and falls in water level. They usually arise as a result of gravitational attraction of the moon and sun on the earth. Water level recordings are done with the aid of manual tide gauges, automatic tide gauges and water level recorders. There are a number of needs for water level information. The most popular use of water level information is for navigation. Water level information is also important in harbour and near shore engineering constructions, flood management, hydrographic survey and in oil exploration and exploitation activities. Tides are often analysed and predicted to assist in planning and management decisions taking. Tidal harmonic analysis is usually used to analyse and predict tides.

Tidal harmonic analysis was first developed by William Thomson (later Lord Kelvin) in England in 1867, but was developed independently in 1874 in the U.S. by William Ferrel [1]. In England, Thomson's work was modified and improved by Darwin [2] and Doodson [3,4, 5]. In the U.S., Ferrel's work was modified and improved by Rollin Harris and Paul Schureman [1].

D. Lee Harris in the 1960's used a least squares harmonic analysis technique for tidal analysis [6]. Other versions of harmonic analysis have been developed, as well as other types of tidal analysis techniques, of which the response method of [7] is best known. Godin [8] concentrated on tidal analysis and prediction. His work was the basis for the analysis and predictions programs by [9]. In [10] Godin goes well beyond analysis and prediction and includes a great deal of hydrodynamics, including nonlinear effects. Changing Sea Levels by [11] has four chapters on tides including one on analysis and prediction. Tidal prediction equation is generally used to predict a series of tidal heights from which the times and heights of high and low waters are calculated for each tidal cycle.

Tianhang and Vanicek [12] used sequential least squares adjustment for tidal analysis and prediction. For seven tidal constituents with fifteen unknowns, sixty six percent of central processing unit time was saved by using the sequential least squares adjustment over standard and conventional least squares adjustment. In [13] the Kalman filtering method was used in determining the parameters of the tide level model. The Kalman filtering method was used to directly estimate the harmonic parameters. The method was however limited to determining the main constituent tides before tidal prediction.

Tsai and Lee [14] applied the back-propagation neural network for real-time prediction of tidal level using field data of diurnal and semi-diurnal tides. Shu [15] carried out tidal prediction using tidal constituents from a neighbouring reference site. The least squares solution of the work was enhanced with some constraints equations to separate the tidal constituents. An application of the 
back-propagation neural network using short-term measuring data was presented by [16]. Tidal level data at Taichung Harbour in Taiwan was used to test the performance of the model. Comparisons with conventional harmonic methods indicate that the backpropagation neural network mode can also efficiently predict the long-term tidal levels.

Centre for Operational Oceanographic Products and Services (CO-OPS) is the government agency responsible for tidal analyses and predictions for coastal waters of the United States. Standard harmonic analyses of observed water level series are made for 37 constituents by CO-OPS. From the analyses, the harmonic constants, amplitude and phase lag are determined for each constituent and used for tidal prediction of high and low water levels. Water level tidal predictions by CO-OPS are given for over 3,000 locations and placed on CO-OPS web site [17].

The United Kingdom hydrographic office developed the Admiralty EasyTide. Admiralty EasyTide is the most comprehensive tidal prediction service on the web, with high and low tidal predictions for over 7000 ports [18]. Admiralty EasyTide is also based on tidal harmonic analyses and prediction and gives free tidal predictions for seven days.

\section{METHODOLOGY}

\subsection{Study Area}

The study area for this work is Lagos harbour. The Lagos harbour is situated in Lagos State, which is in the southwestern part of Nigeria. Lagos harbour serves as the entrance from the Atlantic Ocean to a network of Lagos lagoons, with Lagos and Lekki lagoons being the major lagoons among these lagoons. The other lagoons are Yewa, Badagry, Ologe, Iyagbe, Kuramo, Apese, Epe, and Mahin lagoons [19].

Lagos lagoon empties into the Atlantic Ocean through Lagos Harbour. The Lagos harbour is $0.5 \mathrm{~km}$ to $1 \mathrm{~km}$ wide and $10 \mathrm{~km}$ long. The Lagos bathymetric survey carried out in 2008 by Department of Surveying and Geoinformatics, University of Lagos for Lagos State Government reveals that the water depth of Lagos harbour ranges from $4 \mathrm{~m}$ to $20 \mathrm{~m}$, with an average depth of $11 \mathrm{~m}$. Lagos harbour is tidal. Water from the Atlantic Ocean moves into the Lagos harbour during high tides and receeds during low tides.

Salinity varies within the Lagos lagoon. In the main basin of Lagos lagoon, salinity is always below 3\% during the raining season. During the dry season however, salinities rise to $30 \%$ in Lagos harbour, and to $8-10 \%$ in the main basin of Lagos Lagoon. The surface water temperature of the main basin of the Lagos lagoon varies from $26^{\circ}$ $31.5^{\circ} \mathrm{C}$ throughout the year, reaching maxima during the wet season [20].
The origin of erosion in Victoria Island, Lagos State can be traced to the construction of two breakwaters between 1908 and 1912 at the entrance to Lagos harbour from the sea. Lagos harbour was known to be constantly silted thereby constituting a navigational hazard to ships going into Lagos harbour [21 and 22]. The construction of these breakwaters which are almost perpendicular to the coastline and projecting into the Atlantic Ocean affected the normal flow of sediments, which on this part of the Nigerian coast is from west to east. Although the construction of two breakwaters solved the problem of siltation, it starved Victoria Island beach which is on the east of the breakwater of sediments. So, while areas on the west of the breakwaters were accreting, Victoria Island which is on the east was experiencing acute erosion. Eko Atlantic City is being built around the entrance of Lagos harbour as a hard-core engineering solution to perennial erosion in Victoria Island. This gigantic project has only succeeded in raising the mean sea level in Lagos State and in transferring erosion from Victoria Island to other parts of Lagos State.

The Lagos harbour is the economic nerve centre of the county and provides access to Lagos and Tin Can ports. Lagos and Tin Can ports handle a greater percentage of imported goods and products into Nigeria. Many industries and headquarters of banks are situated in the vicinity of Lagos harbour as a result of the commercial activities around Lagos and Tin Can Ports. Figure 1 shows a Google earth image of Lagos harbour area.

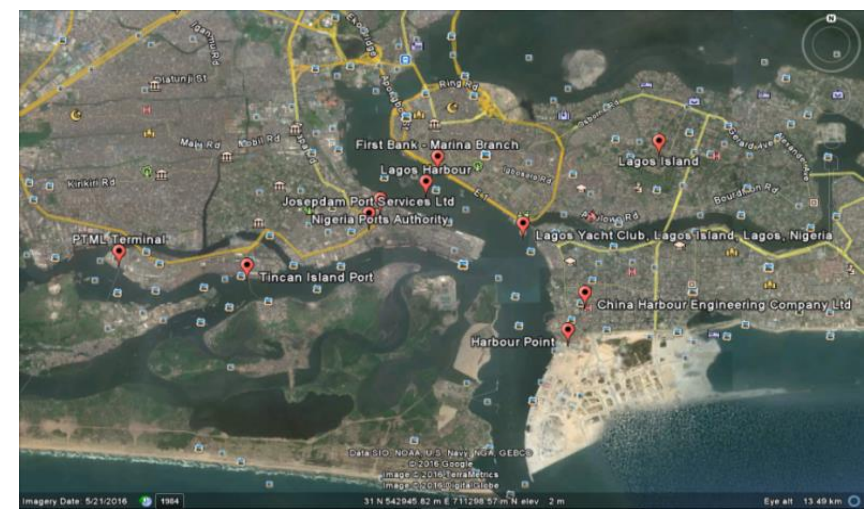

Figure 1: Google earth image of Lagos harbour area

\subsection{Data Acquisition}

The tidal observation for this work was obtained from Nigerian Institute for Oceanography and Marine Research (NIOMR) permanent sea level tide gauge station situated at Lagos harbour. The observed tidal data covered a period of 523 hours (from January 9, 2014 to January 31, 2014). The tide gauge zero is $2.9063 \mathrm{~m}$ and is tied to the Lagos survey datum of $2.8310 \mathrm{~m}$. The mean sea level tidal observations were converted to hourly heights above chart datum. The 
chart datum at Lagos harbour is $0.31 \mathrm{~m}$ below the mean sea level at Lagos harbour.

The tidal observations were approximate as a result of shipping activities at the Lagos harbour. The observed tidal data above chart datum were subjected to a median filter to remove spikes in the data. The essence of the median filter was to run through the tidal data one by one, substituting each tidal data with the median of neighboring tidal data [23].

\subsection{Harmonic Analysis of Tides}

The basic equation for carrying out harmonic analysis of tide is given by [24] as:

$$
h(t)=S_{0}+\sum_{t=1}^{n}\left(H_{i} \operatorname{Cos}\left[\omega_{i} t+\alpha_{i}\right]\right)
$$

In (1), $\omega_{\mathrm{i}}$ is the angular frequency of the tidal constituent $\mathrm{I}, \mathrm{H}_{\mathrm{i}}$ is the amplitude of tidal constituent $\mathrm{I}, \mathrm{S}_{\mathrm{o}}$ is the height of mean sea level above the datum used, $t$ is the time, $n$ is the number of harmonic constituents and $\alpha_{i}$ is the phase of each harmonic constituent.

The orbit of the moon is not constant, but rotates slowly with a period of 18.61 years. The amplitude $(H)$ and phase $(\alpha)$ of each harmonic constituent are not constant but change slowly as a result of the rotation of the orbit of the moon. To take care of the changes in the amplitude $(H)$ and phase $(\alpha)$ of each harmonic constituent, a nodal factor $\mathrm{f}$ and astronomical argument $(\mathrm{v}+\mathrm{u})$ are usually introduced to modify eq. (1) [25]. Introducing this nodal factor $\mathrm{f}$ and $(\mathrm{v}+\mathrm{u})$ gives:

$$
h(t)=S_{0}+\sum_{t=1}^{n}\left(f_{i} H_{i} \operatorname{Cos}\left[\omega_{i} t+\left(v_{i}+u_{i}-\alpha_{i}\right)\right]\right)
$$

In (2), $\mathrm{v}$ is the phase angle at time zero, $\mathrm{u}$ is the nodal angle, and $\mathrm{f}$ and is the nodal factor. Eleven tidal constituents were used for the harmonic analysis; the eleven tidal constituents are shown in Table 1.

\section{Table 1: Tidal Constituents used for Harmonic Analysis}

\begin{tabular}{ccc}
\hline S/N & Constituent Name & Constituent Frequency $\left(\omega_{\mathrm{i}}\right)$ \\
\hline 1. & $\mathrm{M} 2$ & 28.9841042 \\
2. & $\mathrm{~S} 2$ & 30.0000000 \\
3. & $\mathrm{~N} 2$ & 28.4397295 \\
4. & $\mathrm{~K} 2$ & 30.0821373 \\
5. & $\mathrm{~K} 1$ & 15.0410686 \\
6. & $\mathrm{O} 1$ & 13.9430356 \\
7. & $\mathrm{P} 1$ & 14.9589314 \\
8. & $\mathrm{MSf}$ & 1.0158958 \\
9. & $2 \mathrm{~N} 2$ & 27.8953548 \\
10. & $\mathrm{M} 4$ & 57.9682084 \\
11. & $\mathrm{MS} 4$ & 58.9841042 \\
\hline
\end{tabular}

Equations for calculating $\mathrm{v}$ and $\mathrm{u}$ are given by [26], with some minor changes as a result of the direct use of the original astronomical parameters [27]. Basic astronomical parameters are given in equations $3 \mathrm{a}$ to $4 \mathrm{e}$. The time dependent auxiliary coefficients (c) are introduced for their recurrent use and can be rounded to six decimal digits. The longitudes of lunar and solar elements (d) define the long period time dependence of the constituent arguments v; they are expressed as a function of

$$
T=\frac{\left(365 m+i n t\left[\frac{m-1}{4}\right]+0.5\right)}{36525}
$$

where, $\mathrm{T}$ is time expressed in Julian centuries (36 $525 \mathrm{~d}$ ), taken from Greenwich mean noon, December 31, 1899 (Gregorian calendar); $\mathrm{m}$ is time after $0 \mathrm{~h}$, January 1, 1900 in years and the integer part of $(m-1) / 4$ accounts for the leap years $[26,27,28]$. The time dependent elements of the moon's orbit (e) define, according to [26], f and u.

Astronomical arguments $(\mathrm{v}+\mathrm{u})$ and corresponding nodal factor (f) given by [27] were calculated for seven constituents for each observation period in Matlab programming environment using the following constants, equations 3 a to $4 \mathrm{e}$ and equations in Table 2.

The constants used are given as follows:

$c=3.84403 \times 10^{8} \mathrm{~m} \quad$ (mean earth-moon distance) $c_{1}=1.49504201 \times 10^{11} \mathrm{~m}$ (mean earth-sun distance)

$$
\begin{aligned}
& \frac{S}{E}=332488 \pm 43 m \quad\left(\frac{\text { sun }}{\text { earth }} \text { mass ratio }\right) \\
& \frac{M}{E}=12289 \pm 4 \times 10^{-6} \\
& =\frac{1}{81.37}(\text { moon earth mass ratio) } \\
& \frac{S}{M}=2.705455 \times 10^{7} \mathrm{~m} \quad \text { (sun moon mass ratio) } \\
& S^{\prime}=\left(\frac{c}{c_{1}}\right)^{3} \frac{S}{M}=0.45987564 \quad \text { (solar factor) } \\
& \mathrm{e}=0.05490056 \quad \text { (eccentricity of moon's orbit) } \\
& \mathrm{i}=5.14537628^{\circ}
\end{aligned}
$$

(inclination of moon's orbit to plane of ecliptic) The time dependent parameters are:

$$
\begin{gathered}
e_{1}=0.01675104-4.180 \times 10^{-7} \mathrm{~m}-1.26 \times 10^{-11} \mathrm{~m}^{2} \\
\quad(\text { eccentricity of earth's orbit) } \\
\begin{array}{c}
\omega=23.452294^{\circ}-1.30111^{\circ} \times 10^{-4} \mathrm{~m} \\
\text { (obliquity of the ecliptic) }
\end{array}
\end{gathered}
$$

Time Dependent Auxiliary Coefficient are:

$$
\begin{gathered}
A=S^{\prime} \frac{\left(1+\frac{3}{2} e_{1}^{2}\right)}{\left(1+\frac{3}{2} e^{2}\right)} \\
A_{1}=\cos i \cos \omega \\
A_{2}=\sin i \sin \omega \\
A_{3}=\frac{\cos \frac{1}{2}(\omega-i)}{\cos \frac{1}{2}(\omega+i)} \\
A_{4}=\frac{\sin \frac{1}{2}(\omega-i)}{\sin \frac{1}{2}(\omega+i)}
\end{gathered}
$$




$$
\begin{gathered}
A_{5}=A \sin 2 \omega \\
A_{6}=A \sin ^{2} \omega \\
B_{1}=\left\{\cos \frac{\omega}{2} \cos \frac{i}{2}\right\}^{-4} \\
B_{2}=\left\{A_{5}+\left(1-\frac{3}{2} \sin ^{2} i\right) \sin 2 \omega\right\}^{-2} \\
B_{3}=\left\{A_{6}+\left(1-\frac{3}{2} \sin ^{2} i\right) \sin ^{2} \omega\right\}^{-2} \\
B_{4}=\left\{\sin \omega \cos ^{2} \frac{\omega}{2} \cos ^{4} \frac{i}{2}\right\}^{-1} \\
B_{5}=2 A_{5} B_{2} B_{6}=2 A_{6} B_{3} \\
B_{7}=\left\{\begin{array}{c}
\left(1-\frac{3}{2} \sin ^{2} i\right) \\
A
\end{array}\right\}^{-2}=B_{2} A_{5}^{2}=B_{3} A_{6}^{2}
\end{gathered}
$$

Longitude of lunar and solar elements are given by:

$$
h=279.696678^{\circ}+36000.768925^{\circ} \mathrm{T}+3.025^{\circ} \times 10^{-4} \mathrm{~T}^{2}
$$

$$
\text { (mean longitude of sun) }
$$

$$
\begin{aligned}
s=270.437422^{\circ} & +481267.892000^{\circ} \mathrm{T}+2.525^{\circ} \\
& \times 10^{-3} \mathrm{~T}^{2}+1.89^{\circ} \times 10^{-6} \mathrm{~T}^{3}
\end{aligned}
$$

$\mathrm{s}$ is the mean longitude of moon.

$$
\begin{gathered}
p=334.328019^{\circ}+4069.032206^{\circ} \mathrm{T}-1.0344^{\circ} \times 10^{-2} \mathrm{~T}^{2} \\
-1.25^{\circ} \times 10^{-5} \mathrm{~T}^{3} .
\end{gathered}
$$

$p$ is the longitude of lunar perigee.

$$
\begin{gathered}
N=259.182533^{\circ}-1934.142397^{\circ} \mathrm{T}+2.106^{\circ} \times 10^{-3} \mathrm{~T}^{2} \\
+2.22^{\circ} \times 10^{-6} \mathrm{~T}^{3} .
\end{gathered}
$$

$N$ is the longitude of moon's node.

Time dependent elements of the lunar orbit are given by the following equations:

$\mathrm{I}=\cos ^{-1}\left\{A_{1}-A_{2} \cos \mathrm{N}\right\}$

(obliquity of lunar orbit with respect to earth's equator) (4a)

$$
\begin{array}{r}
\mathrm{C}=\tan ^{-1}\left\{A_{3} \tan \frac{\mathrm{N}}{2}\right\} \\
\mathrm{v}=\mathrm{C}-\tan ^{-1}\left\{A_{4} \tan \frac{\mathrm{N}}{2}\right\}
\end{array}
$$

(right ascension of lunar intersection)

$$
\mathrm{v}^{\prime}=\tan ^{-1}\left\{\frac{\sin 2 \mathrm{I} \sin v}{A_{5}+\sin 2 \mathrm{I} \cos v}\right\}
$$

(auxiliary term for K1)

$2 \mathrm{v}^{\prime \prime}=\tan ^{-1}\left\{\frac{\sin ^{2} \mathrm{I} \sin 2 v}{A_{6}+\sin ^{2} \mathrm{I} \cos 2 v}\right\}$

(auxiliary term for $\mathrm{K} 2$ )

The Nodal factors $\mathrm{f}$ and astronomical arguments $\mathrm{v}$ and $\mathrm{u}$ for the remaining four tidal constituents were derived from the nodal factors and astronomical arguments $\mathrm{v}$ and $\mathrm{u}$ of the seven constituents given in Table 3. Table 3 shows the relationships between the various nodal factors and astronomical arguments.

Table 2: Time Dependent Nodal Factors, Arguments and Speeds of Seven Major Harmonic Component Tides

\begin{tabular}{lllll}
\hline Constituent & $\mathrm{f}$ & $\mathrm{v}$ & $\mathrm{u}$ & $\sigma$ \\
\hline $\mathrm{M}_{2}$ & $\mathrm{~B}_{1} \cos ^{4} \frac{\mathrm{I}}{2}$ & $2 \tau-2 s+2 h$ & $2 \xi-2 v$ & $28.984104214-10.14 \times 10^{-9} \mathrm{~T}$ \\
$\mathrm{~S}_{2}$ & $\mathrm{I}$ & $2 \tau$ & 0 & 30.000000000 \\
$\mathrm{~N}_{2}$ & $\mathrm{~B}_{1} \cos ^{4} \frac{\mathrm{I}}{2}$ & $2 \tau-3 s+2 h+\mathrm{p}$ & $2 \xi-2 v$ & $28.439729516-28.16 \times 10^{-9} \mathrm{~T}$ \\
$\mathrm{~K}_{2}$ & $\left\{\mathrm{~B}_{3} \sin ^{4} \mathrm{I}+\mathrm{B}_{6} \sin ^{2} \mathrm{I} \cos 2 v+\mathrm{B}_{7}\right\}^{\frac{1}{2}}$ & $2 \tau+2 h$ & $-2 v^{\prime \prime}$ & $30.082137278+1.38 \times 10^{-9} \mathrm{~T}$ \\
$\mathrm{~K}_{1}$ & $\left\{\mathrm{~B}_{2} \sin ^{2} 2 \mathrm{I}+\mathrm{B}_{5} \sin 2 \mathrm{I} \cos v+\mathrm{B}_{7}\right\}^{\frac{1}{2}}$ & $\tau+h-90^{\circ}$ & $-v^{\prime}$ & $15.041068639+0.69 \times 10^{-9} \mathrm{~T}$ \\
$\mathrm{O}_{1}$ & $\mathrm{~B}_{4} \sin \cos ^{2} \frac{\mathrm{I}}{2}$ & $\tau-2 s+h+90^{\circ}$ & $2 \xi-v$ & $13.943035575-10.84 \times 10^{-9} \mathrm{~T}$ \\
$\mathrm{P}_{1}$ & $\mathrm{I}$ & $\tau-h+90^{\circ}$ & 0 & $14.958931361-0.69 \times 10^{-9} \mathrm{~T}$ \\
\hline
\end{tabular}

Source: [27]. Here, $\tau$ is the $15^{\circ} \mathrm{t}+180^{\circ}, \mathrm{t}$ is the Greenwich time in hours and $\sigma$ is the Angular speed in ${ }^{\circ} /$ hour $^{\circ}$

Table 3: Relationships between various nodal factors and astronomical arguments

\begin{tabular}{ccccc}
\hline $\mathrm{S} / \mathrm{N}$ & Constituent name & Constituent speed $\left(\omega_{\mathrm{i}}\right)$ & Nodal factor $\left(\mathrm{f}_{\mathrm{i}}\right)$ & $\begin{array}{c}\text { Astronomical argument } \\
\left(\mathrm{v}_{\mathrm{i}}+\mathrm{u}_{\mathrm{i}}\right)\end{array}$ \\
\hline 1. & $\mathrm{MSf}$ & 1.0158958 & $\mathrm{f}$ of $\mathrm{M}_{2}$ & $360-(\mathrm{v}+\mathrm{u})$ of $\mathrm{M}_{2}$ \\
2. & $2 \mathrm{~N}_{2}$ & 27.8953548 & $\mathrm{f}$ of $\mathrm{M}_{2}$ & $2 \times(\mathrm{v}+\mathrm{u})$ of $\mathrm{N}_{2}-(\mathrm{v}+\mathrm{u})$ of $\mathrm{M}_{2}$ \\
3. & $\mathrm{M}_{4}$ & 57.9682084 & f of $\left.\mathrm{M}_{2}\right)$ & $2 \times(\mathrm{v}+\mathrm{u})$ of $\mathrm{M}_{2}$ \\
4. & $\mathrm{MS}_{4}$ & 58.9841042 & fquared & $(\mathrm{v}+\mathrm{u})$ of $\mathrm{M}_{2}$ \\
\hline
\end{tabular}

The tidal harmonic analysis model in eq.(2) can be expanded using trigonometric functions as:

$$
h(t)=S_{0}+\sum_{t=1}^{n}\left(f_{i} H_{i} \operatorname{Cos}\left[\omega_{i} t+\left(v_{i}+u_{i}\right)\right] \operatorname{Cos} \alpha_{i}\right)+\sum_{t=1}^{n}\left(f_{i} H_{i} \operatorname{Sin}\left[\omega_{i} t+\left(v_{i}+u_{i}\right)\right] \operatorname{Sin} \alpha_{i}\right)
$$

Let $A_{i}=H_{i} \operatorname{Cos} \alpha_{i} \quad$ and $\quad B_{i}=H_{i} \operatorname{Sin} \alpha_{i}$ 
The tidal harmonic and prediction model becomes:

$$
h(t)=S_{0}+\sum_{t=1}^{n}\left(\left(A_{i} f_{i} \operatorname{Cos}\left[\omega_{i} t+\left(v_{i}+u_{i}\right)\right]\right)+\left(B_{i} f_{i} \operatorname{Sin}\left[\omega_{i} t+\left(v_{i}+u_{i}\right)\right]\right)\right)
$$

Matrix A will therefore be created in the following form:

\begin{tabular}{|cccc}
$\mathrm{S}_{0}$ & $\mathrm{~A}_{1}$ & $\mathrm{~B}_{1}$ & $\mathrm{~A}_{2} \ldots \ldots$. \\
1 & $f_{1} \operatorname{Cos}\left[\omega_{1} t_{1}+\left\{v_{1}+u_{1}\right\}\right] f_{1} \operatorname{Sin}\left[\omega_{1} t_{1}+\left\{v_{1}+u_{1}\right\}\right] f_{2} \operatorname{Cos}\left[\omega_{2} t_{1}+\left\{v_{1}+u_{1}\right\}\right] f_{2} \operatorname{Sin}\left[\omega_{2} t_{1}+\left\{v_{1}+u_{1}\right\}\right] \ldots .$. \\
1 & $f_{1} \operatorname{Cos}\left[\omega_{1} t_{2}+\left\{v_{1}+u_{1}\right\}\right] f_{1} \operatorname{Sin}\left[\omega_{1} t_{2}+\left\{v_{1}+u_{1}\right\}\right] f_{2} \operatorname{Cos}\left[\omega_{2} t_{2}+\left\{v_{1}+u_{1}\right\}\right] f_{2} \operatorname{Sin}\left[\omega_{2} t_{2}+\left\{v_{1}+u_{1}\right\}\right] \ldots \ldots$ \\
1 & $f_{1} \operatorname{Cos}\left[\omega_{1} t_{n}+\left\{v_{1}+u_{1}\right\}\right] f_{1} \operatorname{Sin}\left[\omega_{1} t_{n}+\left\{v_{1}+u_{1}\right\}\right] f_{2} \operatorname{Cos}\left[\omega_{2} t_{n}+\left\{v_{1}+u_{1}\right\}\right] f_{2} \operatorname{Sin}\left[\omega_{2} t_{n}+\left\{v_{1}+u_{1}\right\}\right]$
\end{tabular}

Five hundred and twenty three (523) tidal observations were available for this work. Five hundred (500) hourly tidal observations were used for harmonic analysis. The remaining twenty-three (23) hourly tidal observations were used for the validation of predicted tidal data. A total of twenty-three unknowns were solved for in the trigonometric equation. Five hundred hourly tidal data form the vector of observations. Least squares adjustment method was used to solve for the unknown parameters. The least squares adjustment solution is given as:

$$
\begin{gathered}
X=\left(A^{T} P A\right)^{-1} A^{T} P L \\
X=\left[S_{0}, A_{1}, B_{1}, \ldots \ldots \ldots A_{n}, B_{n}\right]^{T} \\
L=\left[h_{1}, h_{2}, \ldots \ldots \ldots h_{n}\right]^{T}
\end{gathered}
$$

Where $\mathrm{P}$ is unit weight matrix.

The normal equation $\left(A^{T} P A\right)$ is near singular and thus the unknown parameters $\mathrm{X}$ were determined by using conjugate gradient method. This method was discussed extensively in [28]. With the values of the unknown parameters in eq.(9) computed, and the values of $f_{i}$ and $\left(v_{i}+u_{i}\right)$ obtained from equations 3 a to $4 \mathrm{e}$ and Table 2, [29] solve for the harmonic constant $\alpha_{\mathrm{i}}$ as follows:

$$
\begin{aligned}
\operatorname{Tan}_{i} & =\frac{B_{i}}{A_{i}}=\frac{H_{i} \operatorname{Sin} \alpha_{i}}{H_{i} \operatorname{Cos} \alpha_{i}} \\
\alpha_{i} & =\operatorname{Tan}^{-1}\left(\frac{B_{i}}{A_{i}}\right)
\end{aligned}
$$

$\mathrm{H}_{\mathrm{i}}$ can also be determined from the following relationship:

$$
\begin{gathered}
B_{i}=H_{i} \operatorname{Sin}_{i} \\
H_{i}=\frac{B_{i}}{\operatorname{Sin} \alpha_{i}}
\end{gathered}
$$

The harmonic constants determined from equations $11 \mathrm{~b}$ and $12 b$ and the values of $f_{i}$ and $\quad\left(v_{i}+u_{i}\right)$ obtained from $3 \mathrm{a}$ to $4 \mathrm{e}$ and Table 2 were substituted into equation 6 to predict hourly tidal data. Furthermore, tidal predictions were made at 5 minutes' interval using the same equation 6 and changing the hourly time intervals to 5 minutes' interval. A subroutine was written in the same Matlab environment where the main tidal prediction programme is based to determine series of high and low water heights from the tidal predictions made at 5 minutes' intervals. Corresponding times (year, month, day, hour, minute and second) of the high and low water heights were also programmed and concatenated with the predicted tidal data at five minutes' intervals.

\subsection{Box-Pierce Q Statistical Test:}

Box-Pierce Q Statistical test was carried out to determine whether there is white noise in the residual of the observed and predicted tidal data. The auto correlations at lags 1 to 30 were computed using eq.(13) given by [30].

$$
r_{k}=\frac{\sum_{t=k+1}^{n}\left(\left[y_{t}-\bar{y}\right]\left[y_{t-k}-\bar{y}\right]\right)}{\sum_{t=1}^{n}\left(y_{t}-\bar{y}\right)^{2}}
$$

where, $r_{1}$ shows how successive values of $y$ relate to each other, $r_{2}$ shows how $y$ values two periods apart relate to each other, and, $r_{n}$ shows how $y$ values $n$ periods apart relate to each other. The auto correlations at lag $1,2, \ldots$, make up the autocorrelation function (ACF).

A white noise model is a model where observations $y_{t}$ is made of two parts: a fixed value $\mathrm{C}$ and an uncorrelated random error component $\mathrm{e}_{\mathrm{r}}$.

$$
y_{t}=C+e_{r}
$$

For uncorrelated data (a time series which is white noise), we expect each autocorrelation to be close to zero. The error component in this work was determined by using the following relationship given by [31]:

$$
e_{r}=y_{o b s_{t}}-\text { ypre }_{t}
$$

where, yobs $\mathrm{s}_{\mathrm{t}}$ is observed tidal data at time $\mathrm{t}$ and ypre $\mathrm{t}_{\mathrm{t}}$ is the predicted tidal data at time $t$.

The autocorrelations at lags 1 to 30 were computed using equation (13).

\subsection{Root Mean Square Error}

The Root-Mean-Square error (RMSE) of the observed data beyond data used for tidal harmonic analysis and predicted tidal data was found using:

$$
R M S E \sqrt{\left(\frac{1}{n} \sum_{i=1}^{n} e_{i}^{2}\right)}
$$

where, $\mathrm{e}_{\mathrm{i}}$ is the predicted tide at time and $\mathrm{i}$ - observed tide at time $\mathrm{I}, \mathrm{n}=23$

\section{RESULTS AND DISCUSSION OF RESULTS}

\subsection{Results}

The results of the least squares harmonic analysis are presented in this section. Table 4 shows the solution of 
the least squares adjustment and the residuals from the least squares adjustment. The tidal characteristics of the eleven tidal constituents used for the adjustment are shown in Table 5; while Figure 2 shows predicted tides above chart datum for Lagos harbour for June 1, 2017. Figure 3 shows high and low water prediction for Lagos harbour from June 1-4, 2017.

Table 4: Least squares solution and residuals from least squares adjustment

\begin{tabular}{lll}
\hline S/N & Least Squares Solution $(X)$ & $\begin{array}{l}\text { Residuals } \\
\text { Adjustment }(\mathrm{V}=A X-L)\end{array}$ \\
\hline 1 & 1.302179 & $7.37 \mathrm{E}-12$ \\
2 & -0.11913 & $9.78 \mathrm{E}-11$ \\
3 & 0.382827 & $4.23 \mathrm{E}-11$ \\
4 & -0.45112 & $6.07 \mathrm{E}-10$ \\
5 & -0.12865 & $-7.41 \mathrm{E}-10$ \\
6 & -0.19292 & $-7.77 \mathrm{E}-11$ \\
7 & 0.057184 & $-8.21 \mathrm{E}-11$ \\
8 & 0.574465 & $7.01 \mathrm{E}-11$ \\
9 & -0.01357 & $1.21 \mathrm{E}-09$ \\
10 & -0.01596 & $2.64 \mathrm{E}-09$ \\
11 & 0.304057 & $4.49 \mathrm{E}-10$ \\
12 & -0.0013 & $-2.91 \mathrm{E}-12$ \\
13 & -0.02475 & $1.10 \mathrm{E}-11$ \\
14 & -0.0179 & $-2.40 \mathrm{E}-09$ \\
15 & -0.15399 & $3.69 \mathrm{E}-11$ \\
16 & -0.01148 & $6.40 \mathrm{E}-11$ \\
17 & -0.00528 & $-7.10 \mathrm{E}-11$ \\
18 & -0.02146 & $-8.22 \mathrm{E}-11$ \\
19 & -0.03693 & $1.01 \mathrm{E}-12$ \\
20 & 0.003981 & $-8.23 \mathrm{E}-10$ \\
\hline
\end{tabular}

\begin{tabular}{lll}
\hline S/N & Least Squares Solution $(X)$ & $\begin{array}{l}\text { Residuals from } \\
\text { Adjustment }(V=A X-L)\end{array}$ \\
\hline 21 & 0.008997 & $-1.12 \mathrm{E}-09$ \\
22 & 0.000457 & $2.50 \mathrm{E}-10$ \\
23 & 0.008568 & $1.24 \mathrm{E}-09$ \\
\hline
\end{tabular}

Predicted tides were made from the beginning of the tidal observation in January 9, 2014 to June 1, 2017. A sample of hourly observed and predicted tidal data above chart datum is presented in Figure 4. Figure 5 shows observed data beyond data used for analysis and predicted tidal data above chart datum. The results of the auto correlations at lags 1 to 30 is shown in autocorrelation plot in Figure 6. The Root Mean Square Error (RMSE) is $0.026 \mathrm{~m}$.

\subsection{Discussion of Results}

The results from the least squares adjustment done in this work gives the mean sea level for Lagos harbour as $1.302 \mathrm{~m}$. Residuals from the least squares adjustment range from $-2.91 \mathrm{E}-12$ to $7.37 \mathrm{E}-12$, errors from the adjustment were minimal.

The tidal characteristics of the eleven constituents used for least squares adjustment shown in Table 6 shows that semi-diurnal constituents MS, S2, N2 and K2 has the highest amplitudes and are the most significant of all the tidal constituents used. The tides at Lagos harbour are semi-diurnal in nature, it is therefore expected that these four constituents should have the highest amplitudes.

The predicted tides above chart datum for Lagos harbour for June 1, 2017 shown in figure 2 shows the lowest water level to be $0.24 \mathrm{~m}$ below chart datum. The predicted tidal curve is also smooth, indicating that all the spikes in the data as a result of vessels movement have been filtered off.

Table 5: Tidal characteristics of the eleven constituents used for least squares adjustment

\begin{tabular}{lllllll}
\hline S/ & $\begin{array}{l}\text { Constituent } \\
\mathrm{N}\end{array}$ & $\begin{array}{l}\text { Constituent } \\
\text { Name }\end{array}$ & $\begin{array}{l}\text { Amplitudes } \\
(\mathrm{H})(\mathrm{m})\end{array}$ & $\begin{array}{l}\text { Nodal Factor } \\
(\mathrm{F})\end{array}$ & $\mathrm{V}+\mathrm{U}(\mathrm{Deg})$ & $\begin{array}{l}\text { Phase } \\
(\mathrm{Deg})\end{array}$ \\
\hline 1 & M2 & 28.9841042 & 0.4009327 & 1.0312165 & 212.6103308 & 107.2847047 \\
2 & S2 & 30.0000000 & 0.4691067 & 1.0000000 & 360.0000000 & 195.9164932 \\
3 & N2 & 28.4397295 & 0.2012135 & 1.0312165 & 222.5386352 & 163.4892168 \\
4 & K2 & 30.0821373 & 0.5746254 & 0.7897748 & 302.3670598 & 358.6469542 \\
5 & K1 & 15.0410686 & 0.3044753 & 0.9078789 & 302.7971692 & 93.0051882 \\
6 & 01 & 13.9430356 & 0.0247876 & 0.8494056 & 254.2922924 & 266.9925836 \\
7 & P1 & 14.9589314 & 0.1550228 & 1.0000000 & 312.4738420 & 263.3707084 \\
8 & MSf & 1.0158958 & 0.0126332 & 1.0312165 & 147.3896692 & 204.7223280 \\
9 & $2 \mathrm{~N} 2$ & 27.8953548 & 0.0427149 & 1.0312165 & 232.4669397 & 239.8382026 \\
10 & M4 & 57.9682084 & 0.0098382 & 1.0634074 & 65.2206616 & 66.1306154 \\
11 & MS4 & 58.9841042 & 0.0085804 & 1.0312165 & 212.6103308 & 86.9469372 \\
\hline
\end{tabular}




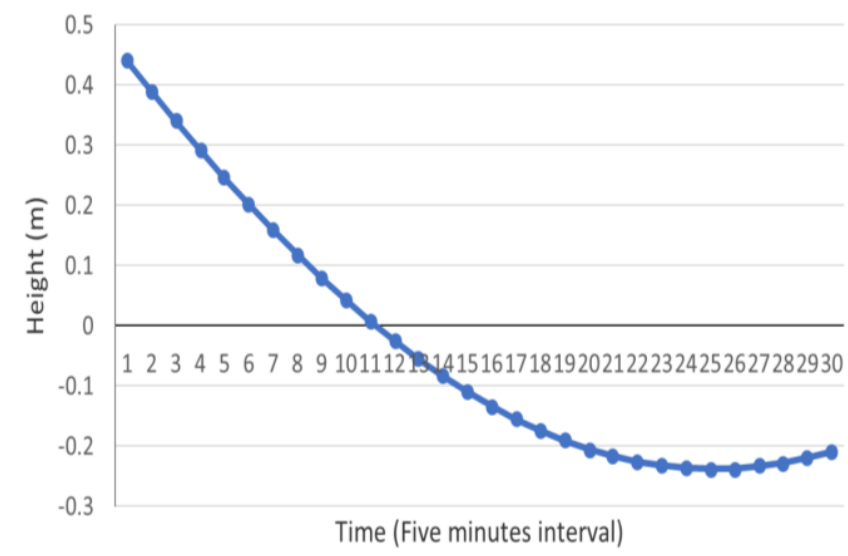

Figure 2: Predicted tides above chart datum for Lagos Harbour for June 1, 2017 at five minutes Interval from 0:00 hour

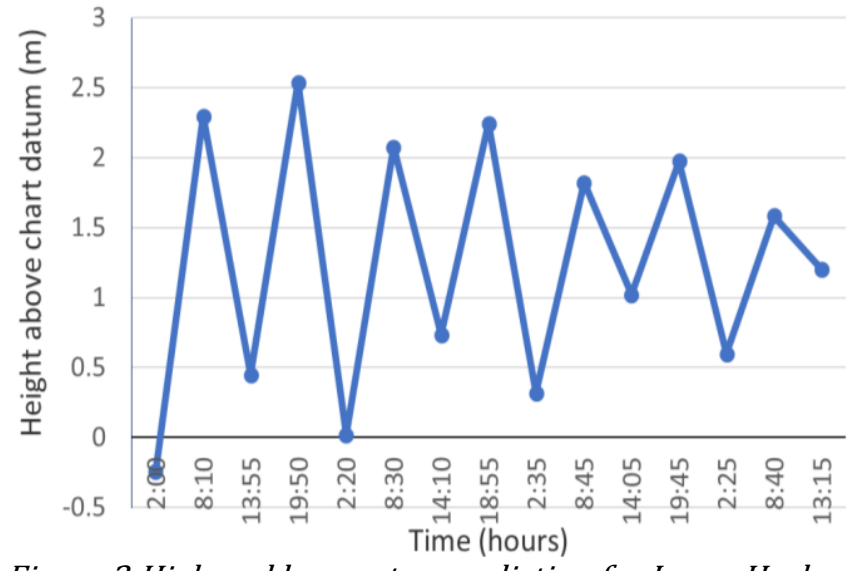

Figure 3:High and low water prediction for Lagos Harbour from June 1-4, 2017
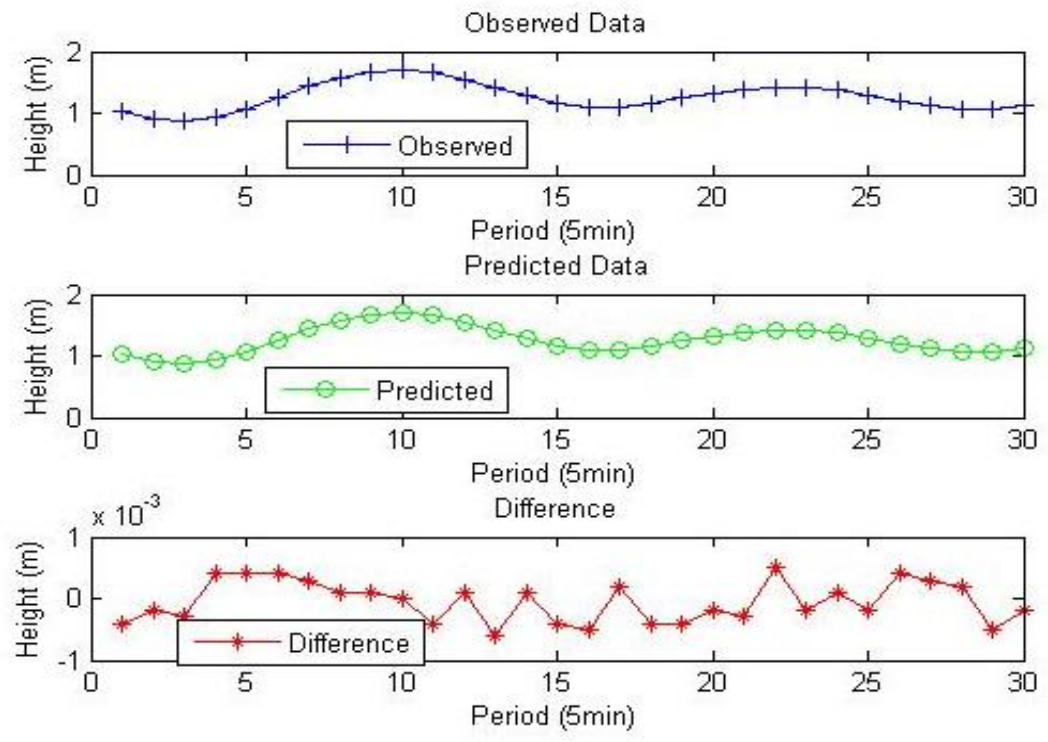

Figure 4: Sample of hourly observed and predicted tidal data above chart datum

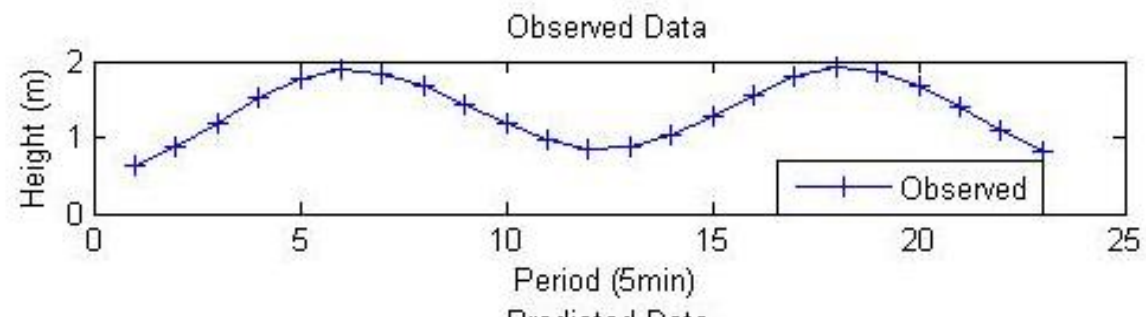

Predicted Data

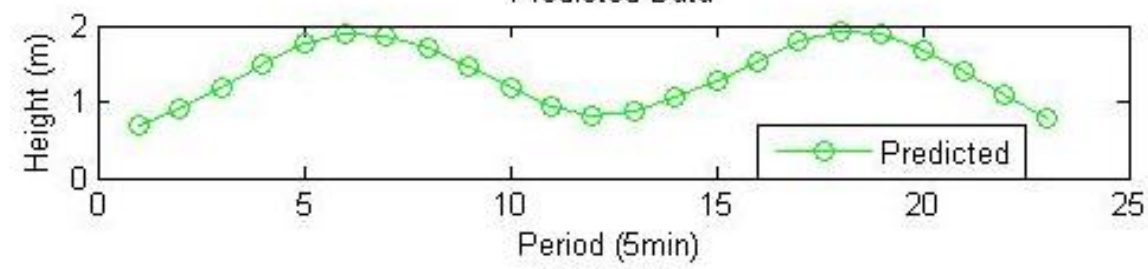

Difference

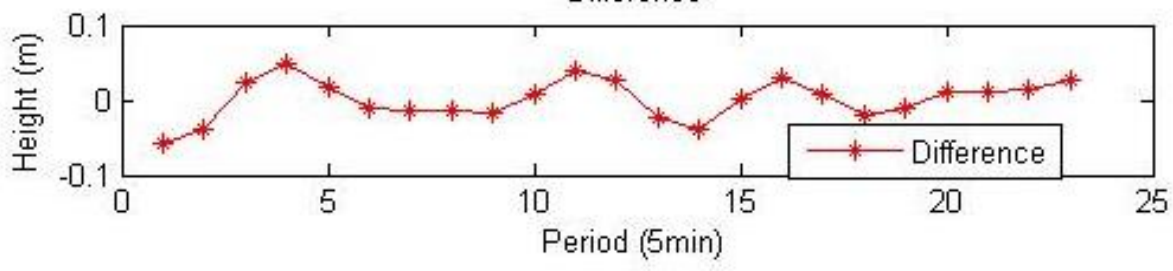

Figure 5: Observed data beyond data used for analysis and predicted tidal data above chart datum 


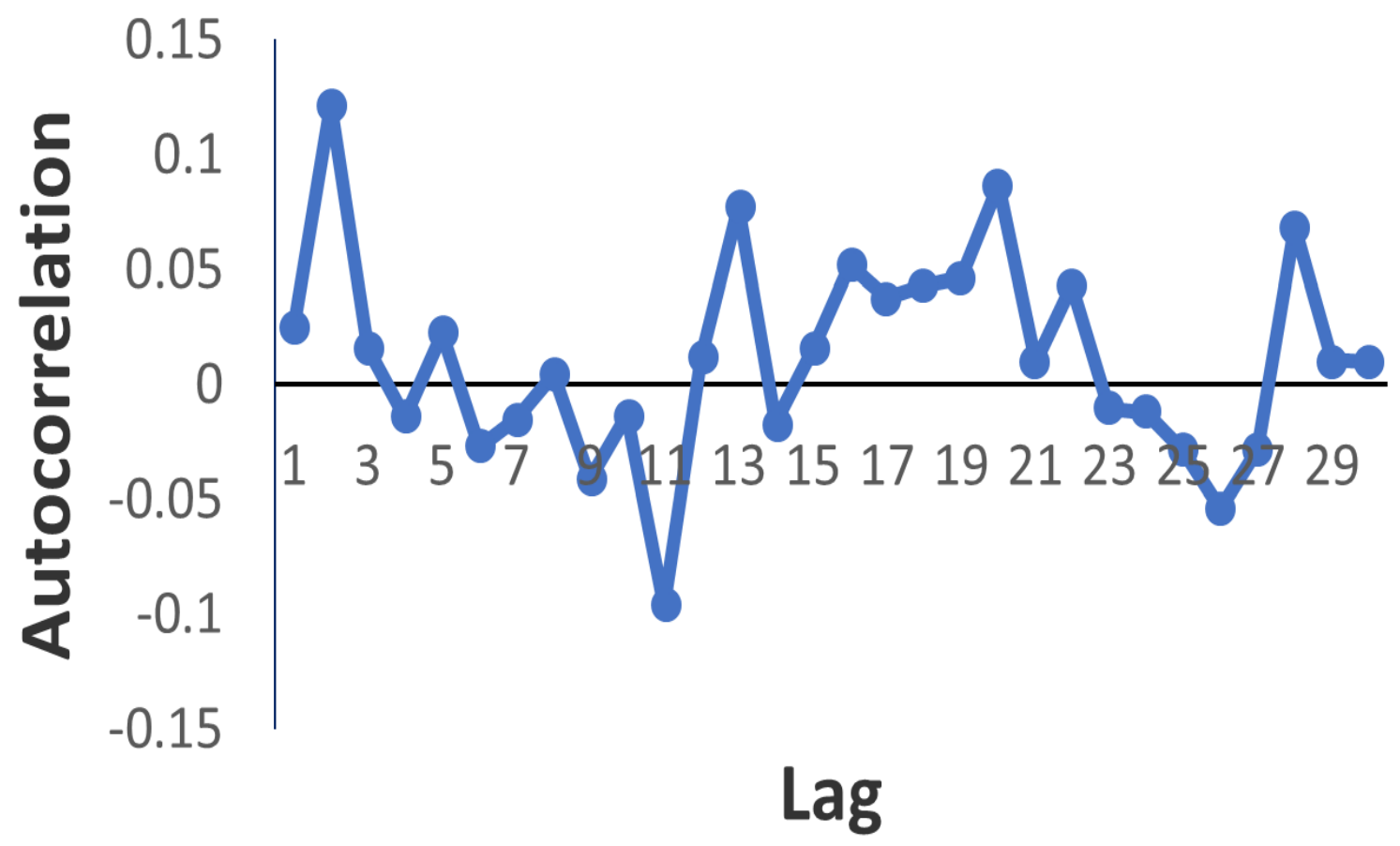

Figure 6: Autocorrelation function

High and low water prediction for Lagos harbour from June 1-4, 2017 shown in Figure 3 shows that successive high and low water heights vary in height and occur at intervals of about 6 hours. The lowest water level was $0.238 \mathrm{~m}$ below chart datum at 02:00 hr on June 1, 2017 while the highest water level was $2.539 \mathrm{~m}$ above chart datum at 19:50 hr on June 1, 2017.

Figure 4 shows sample of hourly observed and predicted tidal data above chart datum. The differences in the sample observed and predicted tides range from $-0.006 \mathrm{~m}$ to $0.005 \mathrm{~m}$. Figure 5 shows observed data beyond data used for analysis and predicted tidal data above chart datum. The differences in the observed data beyond data used for analysis and predicted data range from $-0.057 \mathrm{~m}$ to $0.048 \mathrm{~m}$. Predicted tides beyond data used for analysis therefore have an error of $\pm 0.06 \mathrm{~m}$.

At 95\% confidence interval, it is expected that about 95\% of the autocorrelations for the 30 lags in Figure 6 should be within $-1.96 \sqrt{ } \frac{1}{n} \leq r_{k} \leq 1.96 \sqrt{ } \frac{1}{n}$; therefore $-0.0877 \leq$ $r_{k} \leq 0.0877$. The autocorrelation for 28 of the 30 lags falls within the $95 \%$ confidence, which makes the model acceptable. There is no significant correlation in the range of the 30 lags. The series of residuals of the observed and predicted data is therefore white noise.

\section{CONCLUSION AND RECOMMENDATION}

\subsection{Conclusion}

In this work, 500 hourly water level tidal data derived from Nigerian Institute for Oceanography and Marine Research (NIOMR) permanent sea level tide gauge station situated at Lagos harbour were used to do least squares tidal harmonic analysis.
Autocorrelation at lags 1 to 30 for the residuals of the observed and predicted tidal data shows that there is no significant correlation in the range of the 30 lags. The series of residuals of the observed and predicted tidal data is therefore white noise. The accuracy achieved in this work is high enough to support marine activities around the Lagos harbour.

\subsection{Recommendation}

The following recommendations are made as a result of this research work:

i. More permanent tide gauge stations should be established along the Nigerian coastline.

ii. Real time tidal observation should be made available to the public and research institutions.

iii. The real time tidal observation should be stored in a database for further analysis.

iv. The accuracy of this research work is high enough to support marine activities around Lagos harbour.

v. There is a need to acquire and analyse past and current tidal data covering longer period of time to investigate possible changes in hydrodynamics around the Lagos harbour as a result of the sand filling and construction activities in Eko Atlantic City.

\section{REFERENCES}

[1] National Oceanic and Atmospheric Administration (N.O.A.A.), Tidal Analysis and Prediction, NOAA Special Publication, NOS CO-OPS 3. National Ocean Service, Center for Operational Oceanographic Products and Services, U.S. Department of Commerce, 2007. 
[2] Darwin, G. H. "The harmonic analysis of tidal observations", British Assoc. Report for pp 49-118. 1883,

[3] Doodson, A. T. "The harmonic development of the tide-generating potential“, Proc. Royal Society A, 100, pp 305-329. 1921,

[4] Doodson, A.T. "The analysis of tidal observations", Philosophical Transactions of the Royal Society of London, , 227, pp 223-279. 1928.

[5] Doodson, A. T., "The analysis and prediction of tidal currents from observations of time of slack water", Proceedings of the Royal Society of London Series A, 121(787) pp 72-88. 1928,

[6] Harris, D. L., Pore, N. A. and Cummings, R. "The Application of High Speed Computers to Practical Tidal Problems“, Abstracts of Papers, IAPO, XIII General Assembly, IUGG, Berkeley, Vol. 6, VI-16. 1963,

[7] Munk, W. H. and Cartwright, D. E."Tidal spectroscopy and prediction", Phil. Trans. R. Soc., A, 259, 533-581. 1966.

[8] Godin, G., The Analysis of Tides. University of Toronto Press, Toronto, Canada, 1972.

[9] Foreman, M. G. G. and Henry, R. F., Tidal analysis based on high and low water observations. Pacific Marine Science Report 79-15, Inst. of Ocean Sciences, Patricia Bay, Victoria, B. C., 2004.

[10] Godin, Gabriel, Tides, CICESE, Ensenda, Mexico, 1988

[11] Pugh, D. T., Changing Sea Levels, Effects of Tides, Weather, and Climate, Cambridge University Press, Cambridge, U.K. 2004

[12] Tianhang, H and Vanicek, P., Towards a Real-time Tidal Analysis and Prediction, Department of Surveying Engineering, University of New Brunswick, Fredericton, N.B. Canada, 1988.

[13] Yen, P. H., Jan, C. D., Lee, Y. P., Lee, H. F. “Application of Kalman filter to short-term tide level prediction", Ocean Eng., 122 (5), pp 226-231. 1996.

[14] Tsai, C. P., Lee, T. L., "Back-propagation neural network in tidal-level forecasting", Ocean Eng. ASCE 12 (4), pp 195-202. 1999.

[15] Jian -Jun Shu. "Prediction and Analysis of Tides and Tidal Currents", International Hydrographic Review. Vol. 4. No 2, 2003.

[16] Tsong-Lin Lee. Back-propagation neural network for long-term tidal predictions, Department of Construction Technology, Leader University, Tainan 709, Taiwan, 2003.

[17] Hicks, S. D. Understanding Tides, Center for Operational Oceanographic Products and Services,
National Oceanic and Atmospheric Administration National Ocean Service 2006.

[18]

http://www.ukho.gov.uk/easytide/EasyTide/in dex.aspx, 2017.

[19] Onyema, I. C. The Water Chemistry, Phytoplankton Biomass (Chlorophyll a), Episammic and Periphytic Algae of the Apese Lagoon, Lagos, Report and Opinion, 2009.

[20] www.ramsar.wetlands.org/Portals/ 15/NIGERIA.pdf, 2007.

[21] Ibe, A. C. Coastline Erosion in Nigeria. Ibadan University Press, Ibadan Nigeria, 1988.

[22] Nwilo, P. C. Sea Level Variations and the Impacts along the Nigerian Coastal Areas. Ph.D. Thesis, Environmental Resources Unit, University of Salford, Salford, U.K, 1995.

[23] www/en.wikipedia.org/wiki/Median_ filter, 2012

[24] Doodson, A. T. and Warburg, H. D., Admiralty Manual of Tides, Hydrographic Department, Admiralty. United Kingdom,1941.

[25] Eluwa, E. C., Prediction of Vertical Tides by Least Squares Harmonic Analysis. M.Sc. Degree Project. Department of Surveying and Geoinformatics, University of Lagos, (Unpublished), 1991.

[26] Schureman, P., Manual of harmonic analysis and prediction of tides, Department of Commerce, Coast and Geodetic Survey, Special Publication No. 98. U.S. Government Printing Office, Washington,1958.

[27] Stravisi, F., "The IT method for the harmonic tidal prediction", Bollrtino Di Oceanologia Ed Applicata, 1983, Vol. 1 N.3 Luglio. pp193-204.

[28] Badejo 0. T., Olaleye, J. B. and Alademomi A. S., Prediction of mean water level using short - span tidal records for the University of Lagos lagoon, South Western Nigeria. Journal of Engineering Research JER 17, No. 3. Faculty of Engineering University of Lagos, Nigeria, 2012, pp52-67

[29] Badejo, O. T., Evarie, P., Alademoni, S. and Anorue, N., "Tidal Harmonic Analysis at Bonga Field" FIG Regional Conference. Abuja, Nigeria, 2013.

[30] Box, G.E.P. and Jenkins, G. M.. Time series analysis, forecasting and control, Holden Day Inc., San Francisco, 1972.

[31] Badejo, O. T., Evarie, P., Anorue, N and Alademoni, S. "Harmonic Analysis of Tides at Bonga Oil Field, Nigeria", Journal of Engineering Research, Volume 21 No. 1, 2016. 